\section{O QUE TEM SIDO OU NÃO TEM SIDO A FORMAÇÃO PROFISSIONAL EM EDUCAÇÃO FÍSICA NO BRASIL? REFLEXÕES E PROVOCAÇÕES A PARTIR DA TEORIA DA MODERNIZAÇÃO REFLEXIVA}

\author{
WHAT HAS OR HAS NOT PROFESSIONAL TRAINING IN PHYSICAL \\ EDUCATION BEEN LIKE IN BRAZIL? REFLECTIONS AND PROVOCATIONS \\ FROM REFLEXIVE MODERNIZATION THEORY
}

¿QUÉ HA SIDO, O NO HA SIDO, LA FORMACIÓN PROFESIONAL EN EDUCACIÓN FÍSICA EN BRASIL? REFLEXIONES Y PROVOCACIONES A PARTIR DE LA TEORÍA DE LA MODERNIZACIÓN REFLEXIVA

Ademir Faria Pires*, leda Parra Barbosa-Rinaldi*, Juliano de Souza*
Palavras chave: Educação Física. Currículo. Epistemologia.
Resumo: Este texto, de caráter teórico e bibliográfico, pretende ser uma digressão primeira sobre a formação profissional em Educação Física no Brasil a partir de algumas contribuições abertas pela teoria da modernização reflexiva de Beck e Giddens. Na primeira parte do texto, trazemos alguns insights sobre a dinâmica de modernização reflexiva para pensar a formação profissional na área. Já na segunda seção do manuscrito, procuramos dimensionar o que tem sido, não tem sido e pode vir a ser o processo de formação inicial em EF a partir da recuperação hermenêutica do processo de modernização reflexiva.
Keywords: Physical Education. Epistemology. Curriculum.

Abstract: This theoretical and bibliographical text is intended as an initial reflection on professional training in Physical Education in Brazil based on some contributions put forward by Beck and Giddens' theory of reflexive modernization. The first section presents some insight into the dynamics of reflexive modernization in order to think about professional training in the area. The second section attempts to measure what the initial training process in PE has been, has not been, and may be, based on hermeneutic recovery of the reflexive modernization process.

Palabras clave: Educación Física. Currículo. Epistemología
Resumen: Este texto, de carácter teórico y bibliográfico, pretende ser una primera reflexión sobre la formación profesional en Educación Física en Brasil a partir de algunas contribuciones abiertas por la teoría de la modernización reflexiva de Beck y Giddens. En la primera parte del texto, traemos algunos insights sobre la dinámica de modernización reflexiva para pensar la formación profesional en el área. En la segunda sección del manuscrito, buscamos dimensionar lo que ha sido, lo que no ha sido y lo que puede llegar a ser el proceso de formación inicial en EF a partir de la recuperación hermenéutica del proceso de modernización reflexiva.
* Universidade Estadual de Maringá. Maringá, PR, Brasil. E-mail: afariapires@gmail.com, parrarinaldi@hotmail.com julianoedf@yahoo.com.br

Recebido em: 23/10/2017 Aprovado em: 14/05/2018

DOI: https://doi.org/10.22456/1982-8918.77556 (c) (i) () Licence 


\section{INTRODUÇÃOO}

A Educação Física (EF) como prática institucionalizada e área relativamente autônoma de estudos é pauta dos enfrentamentos científicos e políticos que se radicalizam no contexto social brasileiro. É verdade que, pelo menos desde o final dos anos 1980, os debates envolvendo a EF se mostram acalorados e essa condição nos últimos anos continua se mantendo, sobretudo, em função 1) da Reforma do Ensino Médio (Lei no 13.415/2017), que, num primeiro momento, consistia em retirar a obrigatoriedade da EF como componente curricular (BRASIL, 2017a); 2) do processo de construção da Base Nacional Comum Curricular (BNCC), documento pensado como referência nacional para a elaboração dos currículos dos sistemas e redes escolares, tal qual para as propostas pedagógicas que informam a ação profissional (BRASIL, 2017b); e 3) das tensões envolvendo a formação inicial em EF na universidade e o sistema CONFEF/ CREF'.

Considerando este cenário posto como oportuno para novas reflexões, procuramos no presente artigo desenvolver uma digressão primeira sobre a formação profissional em EF a partir de algumas contribuições abertas pela teoria da modernização reflexiva de Ulrich Beck e Anthony Giddens. Como modelo aproximativo de sociedade, entendemos que essa teoria possui fortes correlações com a realidade social, abrindo novas possibilidades analíticas ao campo da EF no Brasil. Justificamos, além disso, a opção pela temática da formação profissional como objeto investigativo, uma vez que é no contexto da formação inicial que se constroem aqueles conhecimentos indispensáveis que atingirão ou não o "chão da escola" (BARBOSARINALDI, 2008) e outros espaços em que a EF é tematizada.

Para levar a cabo essa análise, realizamos uma pesquisa bibliográfica e documental de caráter exploratório, a partir de um quantitativo de textos, artigos e livros que reportam à temática da formação profissional em EF, para, em seguida, explorar e discutir esse material com base na teoria da modernização reflexiva de Beck e Giddens. Salientamos que a escolha por esta teoria, ainda pouco difundida na área da EF, se deu por defendermos que as discussões encontradas nas obras que a sustentam dão suporte para a compreensão da sociedade atual, assim como da formação profissional em EF, sobretudo, no que ela tem sido ou não tem sido no ambiente escolar e em outros contextos de intervenção.

No que se refere ao processo de seleção do corpus bibliográfico, fizemos uso da base de dados do SCiELO e LILACS, haja vista que essas bases contemplam um grande número de produções latino-americanas, bem como de estudos da área de Humanidades. Nesse percurso, nos valemos de uma busca exploratória em seis periódicos nacionais da EF (Movimento, Revista Brasileira de Educação Física e Esporte, Revista Brasileira de Ciências do Esporte, Journal of Physical Education, Pensar a Prática e Motrivivência) que abrangem o escopo dos estudos socioculturais em EF e correspondem aos estratos A2, B1 e B2 do sistema de estratificação Qualis. Além dos artigos de que já tínhamos conhecimento, foi possível então encontrar outros a partir dos termos "Formação profissional" e "Formação profissional em EF", de modo a compormos um aporte representativo para nossa interlocução crítica.

Vale ressaltar que não houve um recorte temporal específico, mas as produções encontradas nas bases e periódicos pesquisados datam inicialmente da década de $1980 \mathrm{e}$ se estendem até 0 ano de 2017. 0 texto que segue está dividido em duas partes. Na primeira

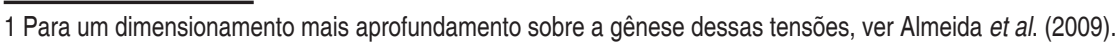


delas, trazemos alguns insights sobre a dinâmica de modernização reflexiva para pensar a formação profissional em EF. Já na segunda seção do manuscrito, procuramos dimensionar o que tem sido, não tem sido e pode vir a ser o processo de formação inicial em EF a partir da recuperação hermenêutica do processo de modernização reflexiva.

\section{A DINÂMICA DE MODERNIZAÇÃO REFLEXIVA - ALGUNS INSIGHTS}

O processo cego e surdo ${ }^{2}$ de modernização reflexiva acentuadamente em marcha no globo desde ao menos o fim da Guerra Fria (GIDDENS, 1991, 1996; BECK, 2011; BECK; BONSS; LAU, 2003) não envolve apenas mudanças estruturais, mas uma mudança qualitativa e subpolítica nas relações entre estrutura e agência humana. Quando a modernização alcança determinado nível, os agentes tendem a se tornar mais individualizados, e suas ações, por assim dizer, já não são meros reflexos de condicionantes estruturais. Sob esse pano de fundo é que é possível então defender que a estrutura tem forçado os atores sociais a um padrão de existência cada vez mais livre e autônomo (LASH; WYNNE, 1992).

Tendo em vista a significação para esta modernização reflexiva, Beck (1997) afirma a possibilidade de uma "(auto) destruição" criativa para toda uma era, referindo-se àquela da sociedade industrial. Tais mudanças são explicitadas de maneira enfática por Beck, Bonss e Lau (2003) quando apontam que a modernização reflexiva parece estar produzindo um novo tipo de capitalismo, de trabalho, de ordem global e de sociedade. Nessa esteira, os autores asseguram que a tarefa central das Ciências Sociais neste momento é investigar o ritmo e direção destas mudanças, que estão acontecendo não apenas nas estruturas sociais, mas para as pessoas que nelas interagem (BECK; BONSS; LAU, 2003).

Da mesma maneira, consoante Giddens (2000), os modos de vida produzidos pela modernidade nos desprendem de todos os tipos habituais de ordem social, sem antecedentes. Para 0 autor, as transformações envolvidas na modernidade, em sua extensionalidade, tal como em sua intencionalidade, são mais complexas que as mudanças típicas de períodos anteriores. E isto porque, simultaneamente, essas transformações provocaram interconexões globais e tocaram nos aspectos mais íntimos e pessoais da existência humana.

Ademais, tanto Beck (2011) quanto Giddens (1991) defendem a existência de uma sociedade destradicionalizada, na qual os agentes e a ação social tendem a se desprenderem das estruturas. Esse aspecto está intimamente ligado ao abandono dos contextos de ação locais e tradicionais, condição esta potencializada pela separação do tempo e do espaço e pelo desenvolvimento de uma dimensão "vazia" do tempo: "A reflexividade institucional tornou-se 0 principal inimigo da tradição" (GIDDENS, 1997, p. 115).

Em outras palavras, temos que a tradição diz respeito à coincidência entre tempo e espaço, mas na atualidade a ação à distância é a que mais corresponde à dinâmica de globalização, na qual tudo está conectado: "[...] a ausência predomina sobre a presença, não na sedimentação do tempo, mas graças à reestruturação do espaço" (GIDDENS, 1997, p. 118). Em acréscimo, tal como afirma Beck (2011), as fronteiras antes estabelecidas são dissolvidas e, por mais que os sujeitos estejam localmente fixados com os "pés ao solo", têm a liberdade

2 Processo cego e surdo pois trata-se de um encadeamento estrutural de ações que acontecem diante de nossos olhos e ouvidos, sem que tenhamos percepção e controle avançados dessa dinâmica de desenvolvimento social. De acordo com Beck (1997), a transição da primeira modernidade para a modernidade reflexiva não diz respeito a uma crise, nem mesmo a uma revolução, e sim a um processo de autoconfrontação e autodissolução ambígua das bases sociais em um estágio avançado do processo civilizatório. 
de pensar, sonhar, investir e comunicar-se globalmente sem maiores dificuldades. O potencial curso de ação global já não é uma capacidade que se restringe a poucos indivíduos e, no bojo desse processo, crianças e jovens cada vez mais crescem em contato com as novas tecnologias e assim vão sendo integrados ao fluxo de uma consciência que passa a ter uma dimensão de alcance cosmopolita (VANDENBERGHE, 2014).

Paralelamente a tais mudanças, opera então a destradicionalização das relações sociais. No que se refere à esfera das relações íntimas, Beck e Beck-Gernsheim (2017) apontam que a instituição familiar na sociedade pós-tradicional é reconfigurada na medida em que casais divorciados, casais de mesmo sexo, famílias constituídas apenas pelo pai ou mãe, pelo sujeito que vive sozinho ou com seu animal de estimação etc., passam a figurar neste cenário. A destradicionalização, todavia, transcende o campo das intimidades e na esfera pública temos esse referente atuando nas diferentes instituições, a exemplo da escola que revê muito de suas regras e pauta suas relações em princípios mais dialógicos e menos hierárquicos.

Outro aspecto importante da modernização reflexiva é a tendência de individualização que, nos dizeres de Giddens (2002), aponta para a "construção do eu" a partir da reflexividade institucional. Este processo pressupõe a desincorporação dos modos de vida da sociedade industrial seguida da reincorporação de outros modos de vida, no sentido de garantir aos indivíduos a construção de suas próprias biografias. Este é um processo que não ocorre de maneira aleatória, ele é potencializado no contexto da modernidade reflexiva (BECK, 1997). Do mesmo modo, o deslocamento do tempo-espaço proporciona referências aos indivíduos na construção de sua autoidentidade, por meio das novas mídias que estabelecem canais de comunicação entre os sujeitos para além das fixações locais (GIDDENS, 2002).

Beck (2011), por conseguinte, assevera que a dinâmica de individualização significa determinados aspectos subjetivo-biográficos do processo civilizatório, além de afirmar que esta característica esteve presente desde a Renascença. $O$ autor entende como equívoco retomar este processo no sentido de "individuação", considerando que a individualização não significa atomismo e é muito mais que a emancipação do sujeito. Acerca da biografia, o autor explica que ela se torna independente de determinações predeterminadas (BECK, 2011).

Para Beck e Beck-Gernsheim (2017), a estruturação de uma "narrativa biográfica do eu" se desvincula de modelos e certezas tradicionais, de controles externos, uma vez que o indivíduo é o responsável pela construção de seu modo de viver. Da mesma maneira, Giddens (2002) declara que a "reflexividade do eu" é um processo contínuo que tudo tende a penetrar, em uma lógica na qual o indivíduo passa por constantes momentos de autointerrogação.

Sob este pano de fundo, as dinâmicas de produção e difusão do conhecimento social se reorganizam. Segundo Giddens (2005), a noção de transmissão estruturada de conhecimentos dentro de uma instituição formal tem se tornado algo muito mais amplo e complexo, já que o aprendizado passa a ocorrer em uma diversidade de ambientes que não só a escola. De acordo com o autor, há uma transição de educação para aprendizado e isso não é irrelevante. Os alunos no papel de aprendizes são figuras sociais curiosas, ativas e que, a todo o momento, extraem informações de múltiplas fontes, não se restringindo apenas ao cenário institucional que é a escola. Desta maneira, todos os tipos de contato e relações com os diversos ambientes proporcionam aprendizado aos alunos, seja por meio dos amigos, vizinhos, visitas em pontos turísticos, museus, pela internet e outros meios de comunicação (GIDDENS, 2005). 
Em se tratando de pontos de inflexão na esfera educacional, Giddens (2005) ainda assevera que a circulação do conhecimento na primeira modernidade se deu, sobretudo, via disseminação e popularização de materiais impressos como livros e jornais. Neste momento, na modernidade tardia, o marco na educação se revela através da inserção das tecnologias de informação por via do acesso cada vez mais amplo a computadores, notebooks, smartphones, tablets, condição que não só favorece como também expressa o distanciamento tempo-espaço e a eficiência dos mecanismos de desencaixe e reencaixe das instituições e relações sociais. Como um reflexo desse fenômeno, os sujeitos passam a estar conectados globalmente na web, tendo a possibilidade de manter contato com pessoas do outro lado do globo e obterem informações por meio de um toque em uma simples pesquisa na plataforma Google. Nesse contexto, a educação em sentido amplo se revoluciona e o "[...] desafio para os professores é aprender a integrar as novas tecnologias da informação às aulas de uma forma significativa e sensata em termos educacionais" (GIDDENS, 2005, p. 408).

Beck (2011), por sua vez, também dedicou algumas palavras ao fenômeno educacional na modernidade reflexiva. Para o autor, a educação tende a permitir e proporcionar ao sujeito, dependendo da duração e do conteúdo, um padrão de ação minimamente razoável em termos de processos reflexivos e de autodescoberta. É necessário ainda ressaltar a importância da educação quando se trata do processo de individualização, tendo em vista que ela pode exercer um trabalho pedagógico realista sobre o indivíduo, preparando-o para atuar no mundo de chances arriscadas, marcado por ambiguidades, oportunidades, aprofundamento social das desigualdades e orientado para um mercado de trabalho que já não contempla a todos (BECK, 2011). Ademais, nessa mesma esteira, Beck e Beck-Gernsheim (2017), ao discutirem a redefinição das relações de gênero na modernidade reflexiva, afirmam que a educação "abriu portas" para indivíduos, proporcionando novas oportunidades, experiências e enfrentamentos. Trata-se de um contexto social de ganhos e perdas e que precisa ser enfrentado por todos.

\section{ESBOÇO DE UMA FORMAÇÃO REFLEXIVA PARA A EDUCAÇÃO FÍSICA}

A fim de que possamos preliminarmente pensar a EF brasileira nos marcos da teoria da modernização reflexiva e, num nível seguinte de esforço, refletir sobre a organização curricular dessa disciplina no Brasil, faz-se necessário entender o que é e qual a função de um currículo. Para o pesquisador Gimeno Sacristán (2000), o currículo está relacionado com a instrumentalização concreta que faz uma instituição de ensino de determinado sistema de conhecimento. Através deste sistema emergem conteúdos, que são materializados por meio de usos quase universais na maioria dos sistemas educativos, mesmo que, de acordo com a história e as particularidades de diferentes contextos, cada sistema adquira suas próprias especificidades (GIMENO SACRISTÁN, 2000).

Nessa esteira, Gimeno Sacristán (2000) ressalta que o currículo é uma maneira de expressar a função socializadora e cultural de determinada instituição, reagrupando em torno deste uma quantidade de subsistemas ou práticas diversas, o que, por sua vez, inclui a prática pedagógica desenvolvida em instituições escolares e universitárias, comumente chamadas de ensino. O currículo tende a firmar, a partir de projeto construído e ordenado, uma conexão entre princípios previamente definidos e sua consecução. É estabelecido como uma prática 
na qual se determinam debates entre diferentes agentes do campo educacional, envolvendo mutuamente alunos que tomam atitudes frente ao projeto curricular e professores que 0 delineiam.

Vale destacar que tanto o ambiente educacional quanto a construção de uma proposta curricular estão sempre envolvidas com instituições poderosas (APPLE, 1982). Diante disso, os agentes externos, políticos e econômicos tendem a influenciar a idealização de uma nova estrutura curricular para um determinado sistema de ensino. Neste sentido, Giddens (2005) afirma que a esfera educacional, na maior parte das vezes, contempla os padrões econômicos e demandas empregatícias de um país. Acontece que, em momentos de mudanças econômicas aceleradas, nem sempre há um casamento perfeito entre as prioridades do sistema educacional e as ofertas de emprego. Deste modo, compreendemos que, para além de qualquer outra razão estruturante, seja esta razão referente ao êxito educacional ou à formação de "sujeitos emancipados", o projeto de educação de um Estado estará sempre alicerçado a instituições econômicas ou políticas, que, de certa maneira, direcionarão seus interesses por meio da escola.

No tocante ao campo da EF, nota-se que, principalmente a partir da década de 1980, inúmeras abordagens pedagógicas, em maior ou menor grau de correspondência com as dinâmicas ambíguas do tecido social, surgiram objetivando implantar novos desafios à disciplina, de modo que o conteúdo deste componente curricular pudesse ser sistematizado. Lara et al. (2007), em estudo realizado com autores destas abordagens, elucidam que a maior parte destas, muito mais do que proporem uma metodologia de ensino, anunciam questões teóricas, ideológicas e identitárias da EF como um todo, permanecendo no mundo das ideias e carentes de uma discussão que conduza a uma efetiva ação docente.

Em que pese esse tipo de crítica que reporta à distância interposta entre teoria e prática da EF, há que se destacar que as inúmeras abordagens pedagógicas - humanista (OLIVEIRA, 1985), aulas abertas (HILDEBRANDT; LAGING, 1986), desenvolvimentista (TANI et al., 1988), construtivista (FREIRE, 1989), sistêmica (BETTI, 1991), crítico-emancipatória (KUNZ, 1991), crítico-superadora (SOARES et al., 1992), plural (DAOLIO, 1994), cultural (NEIRA, 2016), dentre outras - em diferentes medidas e sob múltiplas circunstâncias têm informado a realidade da profissão, isto é, as ações e os encaminhamentos referentes à intervenção na EF. Não por acaso, essas abordagens, algumas mais, outras menos, estão presentes nos documentos que visam orientar a ação dos professores de EF, a exemplo dos Parâmetros Curriculares Nacionais a nível federal (BRASIL, 2000) ou das Diretrizes Curriculares da Educação Básica do estado do Paraná (PARANÁ, 2008) ou da Proposta Curricular do Estado de São Paulo (SÃO PAULO, 2008), dentre outras que poderiam ser elencadas.

Por sinal, a influência dessas abordagens pedagógicas da EF - em proporções ainda em aberto e que requerem um estudo à parte - também se fez notar na elaboração da BNCC. $\mathrm{Na}$ perspectiva da BNCC, a EF emerge por meio das práticas corporais, entendendo que estas são compostas pelo movimento humano no âmbito cultural, definido neste documento de modo dinâmico, diversificado, pluridimensional, singular e contraditório (BRASIL, 2017b). São apresentados para o componente curricular as unidades temáticas brincadeiras e jogos, esportes, ginásticas, danças, lutas e práticas corporais de aventura, não se distanciando dos conteúdos propostos para estruturar as práticas da Educação Física Escolar (EFE) nos últimos anos, a partir das diversas abordagens pedagógicas. 
No tocante às dimensões do conhecimento, a BNCC - diferente do que propõe o modelo de Zabala (1998), amplamente utilizado na EF para definir uma ação pedagógica a partir dos domínios conceitual, procedimental e atitudinal - apresenta uma proposta de trabalho apoiada nos seguintes domínios: experimentação, uso e apropriação, fruição, reflexão sobre a ação, construção de valores, análise, compreensão e protagonismo comunitário (BRASIL, 2017b). Apesar, no entanto, dessa ampliação parecer profícua, os motivos para a existência dessas e não de outras dimensões estão ausentes, além de que a própria maneira com que cada uma destas dimensões deve ser trabalhada com os alunos é um tanto misteriosa ou não está clara.

De qualquer modo, podemos dizer que o esforço de elaboração da BNCC, em alguma medida, está em consonância com os preceitos da modernidade reflexiva e também com 0 que propõe Gimeno Sacristán (2000) quando afirma que os profissionais da educação têm o desafio de construir um novo marco intercultural, de maneira mais ampla e flexível, permitindo a integração de valores, ideias, tradições e novidades, a fim de que a pluralidade, a diversidade, a reflexão crítica e a tolerância sejam assumidas como elementos importantes na construção da identidade individual e coletiva. Sob esse marco, o docente precisa saber como provocar a busca por conhecimentos em seus alunos, de acordo com as circunstâncias, o contexto e suas individualidades (GIMENO SACRISTÁN, 2000).

Além disso, é importante também considerar que a BNCC, como tomada de posição reflexiva (mais propriamente em sua intencionalidade do que em conteúdo), se faz devedora à reflexividade institucional que se deu no campo da EF a partir do final dos anos 1980, com o surgimento de abordagens pedagógicas que marcaram a área como um todo e protagonizaram um embate no sentido de se definir a especificidade da profissão. Com essa ampla produção do conhecimento, além das contribuições dos profissionais da época, a EF começou a ganhar mais legitimidade e seus conteúdos foram estruturados, tendo então uma especificidade figurada (RAMOS, 2012). Em outros termos, isso que está sendo sugerido é parte, sem dúvida, da reflexividade interna do campo da $E F$, se bem que muito mais para fazer valer, ao menos no plano discursivo, certas interpretações teóricas do que propriamente se atentar para os elementos de novidade social que marcam a etapa reflexiva da modernização.

Nesse sentido, cabe reconhecer que, no bojo das distintas abordagens pedagógicas da $E F$, há certa divergência na maneira de conceituar o objeto da área e, mais especificamente, da EFE, sendo este definido em termos como "movimento humano" (TANI et al., 1988), "semovimentar", "cultura do movimento" (KUNZ, 1991; 2000), "cultura corporal" (SOARES et al., 1992), "cultura física" (BETTI, 1992), "cultura corporal de movimento" (BRACHT, 1999; BETTI, 1996), etc. Contudo, entendemos que o objeto deste componente curricular pode ser sintetizado simplesmente na expressão "se-movimentar", uma vez que este sim é central nas práticas circundantes à $E F$, seja na escola ou fora da escola, além de que, a rigor, inexiste movimento humano que não seja corporal. Soma-se a isso que o uso do termo cultura, em que pese suas contribuições para sofisticação do debate, serve mais como indicador de um posicionamento político em relação à matriz biológica, que se fez e se faz predominar na área, do que propriamente um aporte que resguarde e garanta a especificidade da profissão. ${ }^{3}$

Por sua vez, essa observação crítica em relação ao uso do termo "cultura" na designação do objeto da EF se apoia no entendimento de que a referida noção, ao ser tomada de forma

3 Essa crítica está aqui sendo lançada em caráter hipotético e será oportunamente desenvolvida e aprofundada pelo programa de pesquisa implícito a esse texto. Posições intermediárias no trato da relação entre as dimensões biológica e cultural do se-movimentar estão presentes em Oliveira (1985) e em Betti (1996). 
estanque e isolada das demais dimensões sociais, sobretudo da dimensão biológica, não dá conta de apreender o objeto da EF nem tampouco informar sua ação pedagógica, seja na escola ou fora da escola, uma vez que, por meio dela, tem se subjugado a dimensão do "como se-movimentar" ao do "por que se-movimentar", ou seja, reduzido a ação motriz ao significante da ação motriz, corrigindo o reducionismo positivista (que abstraía a dimensão pedagógica do se-movimentar a partir da retomada de processos anátomo-fisiológico-motores), mas ao preço de uma reificação culturalista difícil de ser traduzida na ação prática da intervenção.

Ademais, essas tensões teóricas ainda não são ponto pacífico na área e, não sem razão, se fazem refletir na proposição da BNCC, evidenciando que ainda não há clareza sobre o projeto de EF que se pretende assumir no campo. Passados mais de trinta anos do início da "virada crítica" e "cultural" no âmbito da EF brasileira, verificamos que neste documento não há grandes avanços para além daqueles que outrora já haviam sido imputados por agentes competentes neste universo de atuação profissional e investigação científica. Por mais que a BNCC esteja atenta à especificidade da área, a noção de conteúdos e as dimensões do conhecimento foram minimamente ampliadas em seu teor, o que, por sua vez, não confere transformações para este componente curricular em correspondência com as mudanças drásticas que se revelam na etapa reflexiva da modernização.

Neste sentido, compreendemos que há uma espécie de bloqueio no campo, impedindo a percepção e 0 trato adequado para essas dinâmicas de mudanças e descontinuidades sociais, ocasionando a perpetuação de crenças historicamente constituídas na área de EF no Brasil, crenças essas que abrangem desde a definição dos objetivos da EF à eleição de seus conteúdos, como parte de posicionamentos dissonantes no campo, ideologias versus utopias, que, a rigor, prospectam a conservação de um passado não mais desejável ou a transformação da realidade em um sentido que também não é possível, ou ainda, não de acordo com as necessidades sociais da etapa reflexiva da modernização. Posicionamentos como esse, muitas vezes, se traduzem na elaboração de críticas discutíveis e não atentas igualmente aos avanços e efeitos colaterais do processo de modernização em que a EF como profissão está inserida.

Uma variante dessa tomada deposição pode ser encontrada, por exemplo, nas reflexões de Moreira et al. (2016), quando, ao questionarem a construção da BNCC, chegam à conclusão de que a elaboração deste documento foi norteada pelos interesses de reformadores empresariais, que estabelecem parcerias com o poder público. Tal interesse se materializa, segundo o texto, porque desta maneira é possível garantir as ações pedagógicas da educação básica, a concepção de sociedade, de ser humano e de educação, firmadas para e pela mercantilização da vida. Afirma-se, além disso, que a burguesia estabelece a partir da agenda dos organismos internacionais os direcionamentos para as políticas educacionais em escala global, condensando os interesses imediatos e históricos (MOREIRA et al., 2016).

Na contramão desse tipo de crítica parcial e normativa, pensamos ser mais producente pensarem uma EF que tenha maior grau de correspondência com as demandas da sociedade atual, marcada pela expansão de uma reflexividade social que além de endêmica à sociedade pós-tradicional (GIDDENS, 1991) sinaliza para uma política de vida orientada por um cenário de chances arriscadas (BECK; BECK-GERNSHEIM, 2017). Nesse sentido, é fundamental uma recuperação hermenêutica desta dinâmica por parte de uma proposta pedagógica para a EF, de maneira a se estruturar uma abordagem na qual se valorizem os atores individualizados e reflexivos da modernidade tardia. Nesse contexto, um dos papéis fundamentais da EFE, ao 
aplicar seus conteúdos, poderia ser o de valorizar a reflexividade de seus alunos, ampliando 0 arsenal de experiências sociomotoras dos escolares, valorizando as individualidades e permitindo que os alunos atribuam suas próprias significações às práticas realizadas.

Soma-se ainda às abordagens críticas que têm marcado o seu lugar e definido rumos na área de EF a multiplicação de uso de teorias culturais que, pautadas pelo multiculturalismo, buscam por meio da escola e da educação promover o reconhecimento das diferenças, assim como endossar a diversidade sob a ótica do conceito de pluralidade cultural, abarcando questões que, para além do corte de classe, envolvam gênero, religião, etnia, orientação sexual, etc. (MOREIRA, 2001). De uma EF para a classe trabalhadora, passamos a uma EF para os chamados grupos minoritários. Amplia-se, assim, a abrangência do modelo, mas mantém-se inalterável a ideia de missão social por via da EFE, confundindo meios com fins e perdendo de vista a especificidade da profissão.

Em direção diferente a essas tendências, acreditamos, no entanto, que a EFE tem como seu escopo maior fazer com que os escolares se tornem protagonistas de suas "biografias de movimento", propiciando um ambiente favorável para o potencial aprendizado do se-movimentar, pelo se-movimentar e sobre o se-movimentar (TANI, 1988; KUNZ, 1991). Nesta perspectiva, a EFE assumiria o papel de promotora do movimento humano, atingindo assim o seu objetivo real, e não, como muitos defendem, se tornando um espaço calculado para o cumprimento de metas externas à EF, quer sejam as de origem biológica, psicológica ou social ${ }^{5}$.

Soma-se a este exercício de reflexividade epistêmica proporcionado a necessidade de não subestimar o conhecimento acumulado pelas pessoas comuns, isto é, pelos atores leigos do dia a dia da modernização reflexiva que se valem dos programas de EF e esportes. Uma EF reflexiva, portanto, reabilitaria esse tipo de saber e não desdenharia da capacidade dos agentes refletirem sobre o que fazem enquanto parte do fazer. Isso requer, segundo Giddens (1997), colocar em suspeita o raio de ação dos guardiães, figuras anteriormente reconhecidas e respeitadas pelo conhecimento que detinham, sejam idosos, curandeiros, entidades religiosas, científicas, etc. Para o autor, estes guardiães eram os detentores da "verdade formular", ou seja, tinham seus conhecimentos resguardados pela tradição. Em oposição ao papel social monopolizado pelos guardiães, a partir da modernização reflexiva surgiram especialistas que, a rigor, podem ser qualquer indivíduo que empregue com relativo êxito as habilidades específicas ou padrões de conhecimento que o leigo, de saída, não dispõe (GIDDENS, 1997).

Numa tentativa de aproximar o que está sendo posto frente à realidade da formação profissional em EF, há que se considerar que, em outro estágio de formação societária, o professor detinha uma imagem e respeito semelhantes aos guardiães: os alunos se reportavam a ele como um ser "intocável" e "inquestionável". Atualmente, o docente é visto como mais um especialista que precisa se esforçar para conquistar a atenção de seus alunos, necessitando reforçar o seu papel de detentor de conhecimento para que possa, desta maneira, repassar seus saberes e exercer sua função primeira. Tal como afirma Giddens (1997), a especialização

\footnotetext{
4 Não há espaço aqui para essa discussão. Ela está sendo encarada pelo terceiro autor do manuscrito, em um texto por ora intitulado: Biografias de movimento ou das dimensões biopsicossocioculturais do se-movimentar?. Em linhas gerais, adianta-se que a noção de "biografia de movimento", apoiada nos trabalhos colaborativos de Beck e de Giddens, significa que a escrita da vida dos indivíduos passa pelo semovimentar, sendo, portanto, função precípua da EF, nos mais diferentes espaços, contribuir para que os sujeitos construam suas biografias de movimento de forma pedagógica e prazerosa em benefício tanto de suas existências quanto da convivência social respeitosa.

5 Para melhor compreensão do tema, sugere-se o texto de Soares (1996) que discute a especificidade da área.
} 
é mutável, desincorporada e baseia-se em princípios impessoais; há um caráter descentralizado que permite colocar em xeque a figura do professor como autoridade última.

Ademais, complementa Giddens (1997) que o conhecimento especializado está aberto à reapropriação de qualquer pessoa, necessitando este indivíduo de tempo e de recursos necessários para tal. Neste sentido, um dos fatores imprescindíveis para a formação de um profissional de EF capacitado para exercer uma prática pedagógica condizente com as exigências reflexivas da sociedade pós-tradicional é uma reconfiguração da formação inicial em EF no sentido de dar voz àqueles atores competentes que a realizam e a vivenciam nos diferentes espaços a partir da reapropriação que fazem dos conhecimentos peritos, encurtando, desse modo, o enorme hiato existente entre teoria e realidade.

De acordo com Maffei, Verardi e Pessôa Filho (2016), a formação inicial em EF tem se apresentado de maneira frágil e uma das razões disso é a desvinculação entre o ensino, pesquisa e extensão. Registram também os autores que, a partir da nova legislação para 0 ensino superior, foram poucas as mudanças nos cursos de formação de professores com 0 objetivo de se adequarem às transformações ocorridas. Outro descompasso encontrado pelos pesquisadores repousa na relação entre teoria e prática, tendo em vista que os conhecimentos científicos são muitas vezes distanciados dos transmitidos aos alunos e daqueles vistos na prática concreta do cotidiano escolar (MAFFEl; VERARDI; PESSÔA FILHO, 2016).

Por sua vez, Garíglio (2010) constatou que os conhecimentos adquiridos durante a formação inicial em EF são essenciais para enfrentar o choque de realidade que se apresenta no início da carreira profissional. Neste mesmo estudo, questões como distanciamento entre teoria e prática são também mencionadas como um obstáculo para a formação, assim como 0 modo com que os conteúdos são definidos e tratados por parte dos professores formadores. Tais dificuldades são levantadas a fim de que essas temáticas possam ser investigadas e, posteriormente, tratadas com mais afinco na realidade. De maneira geral, Garíglio (2010) aponta que a formação pedagógica dos futuros profissionais de EFE é uma prática fragilizada, que depende ainda de mudanças nos cursos de formação de docentes, a fim de que a prática pedagógica possa ser conciliada às necessidades concretas dos sujeitos.

Deste modo, o professor de EF precisa se atentar a essa nova realidade que se abre ao processo de ensino-aprendizagem, seja no contexto escolar ou fora dele, considerando que seus alunos são autorais, reflexivos, exigentes e, acima de tudo, adentram aos programas de EF e/ou esportes carregando suas experiências vividas na sociedade pós-tradicional, condição que torna necessário o estabelecimento de estratégias de valorização desta gama de saberes corporais por via das aulas de EF, dos programas esportivos e de lazer.

Atrelada a isto, destaca-se também a necessidade de dar vazão àquelas temáticas e conteúdos que integram os sujeitos em suas experiências significativas no contexto de modernização reflexiva. Em face disso, os alunos enquanto atores sociais, protagonistas da EFE, poderão construir, junto ao professor e colegas, práticas, conteúdos e estratégias que ressignifiquem suas vivências de outrora, valorizando, entretanto, os diferentes pontos de contato dos atores e grupos com a modernidade reflexiva. Em suma, esta proposta teórica para a EF reabilita criticamente o senso comum e questiona o estatuto do conhecimento legítimo e libertador centrado na figura do professor, procurando, portanto, tematizar práticas e interesses culturais que, em termos motores e cognitivos, orientam os estilos de vida das gerações mais atuais. 


\section{CONSIDERAÇÕES FINAIS}

Ao longo deste texto, defendemos a ideia de que não só vivemos em uma sociedade pós-tradicional, como também somos afetados pela expansão de uma reflexividade que impõe novos desafios às diferentes instituições. Tratamos aqui, mais especificamente, de instituições educacionais e localizamos a formação profissional em EF neste cenário. Ademais, argumentamos que na modernidade tardia nos deparamos com a reconstrução de toda uma era, tendo em vista que mudanças profundas ocorreram no conjunto das relações firmadas entre estruturas e agentes sociais. Por seu turno, mudanças sociais drásticas requerem, nos dizeres de Beck (2011), outra forma de tratamento teórico e conceitos mais precisos que sejam capazes de capturar os elementos de novidade social que estruturam a vida.

As propostas teóricas para a EF no Brasil $^{6}$ e, informadas por elas, as discussões em torno da formação profissional na área, são orientadas ainda por verdades formulares produzidas em referência à primeira modernidade e que talvez não deem mais conta de compreender e equalizar alguns dos dilemas e tensões que atualmente se impõem à profissão, em especial no que diz respeito à inserção em um mercado de trabalho marcado por incertezas e inseguranças, não só para o horizonte de ação dos futuros bacharéis, mas também dos futuros licenciados.

Nesse sentido, a incorporação da teoria da modernização reflexiva nas agendas de pesquisa em EF pode ser instrutiva para fundamentar novas reflexões e para informar novas práticas curriculares e profissionais, orientadas pelas reais necessidades da sociedade e pelos problemas concretos daqueles que se valem dos programas de EF, esporte e lazer nos mais diferentes contextos de aprendizagem social, dentro da escola ou fora dela. Em contrapartida, temos a impressão que a formação inicial em EF no Brasil, com suas devidas e destacadas exceções, tem sido orientada por uma série de interesses particularistas de grupos intelectuais que, nutridos por diferentes e divergentes bases teóricas, defendem propostas de EF muitas vezes distantes da realidade, em particular por não levarem em conta as demandas reflexivas daqueles que (sobre)vivem e se valem dos programas de EF e esportes.

À maneira de fechamento do texto, ressaltamos a importância não só de imputar novos direcionamentos à teoria da EF como também de recuperar movimentos teóricos silenciados ou, no mínimo, esquecidos na área, a exemplo da abordagem humanista de Vitor Marinho de Oliveira (SOUZA, 2018), de modo a trazermos os agentes sociais competentes - esses sujeitos autorais do dia a dia da modernização reflexiva - para o centro do processo de construção de uma proposta teórica, curricular e metodológica da EF que vise a um maior grau de correspondência com a realidade e, nesse sentido, nos arme de uma deontologia que possibilite não só enfrentarmos os riscos que se multiplicam no globo, mas também usufruirmos das oportunidades que se abrem em termos de experiências reflexivas, contribuindo para que a profissão avance. 


\section{REFERÊNCIAS}

ALMEIDA, Marco Antonio Bettine; MONTAGNER, Paulo César; GUTIERREZ, Gustavo Luis. A inserção da regulamentação da profissão na área de Educação Física, dez anos depois: embates, debates e perspectivas. Movimento, v. 15, n. 3, p. 275-292, jul./set. 2009.

APPLE, Michael. Ideologia e Currículo. São Paulo: Brasiliense, 1982.

BARBOSA-RINALDI, leda Parra. A ginástica como área de conhecimento na formação profissional em Educação Física: encaminhamentos para uma reestruturação curricular. 2004. 220 f. Tese (Doutorado em Educação Física) - Faculdade de Educação Física, Universidade Estadual de Campinas, 2004.

BARBOSA-RINALDI, leda Parra. Formação inicial em Educação Física: uma nova epistemologia da prática docente. Movimento, v. 14, n. 3, p. 185-207, set./dez. 2008.

BECK, Ulrich. A reinvenção da política: rumo a uma teoria da modernização reflexiva. In: BECK, Ulrich; GIDDENS, Anthony; LASH, Scott. Modernização reflexiva: política, tradição e estética na ordem social moderna. São Paulo: Editora UNESP, 1997. p. 11-71.

BECK, Ulrich. Sociedade de risco: rumo a uma outra modernidade. São Paulo: Editora 34, 2011.

BECK, Ulrich; BECK-GERNSHEIM, Elisabeth. 0 caos totalmente normal do amor. Petropolis: Vozes, 2017.

BECK, Ulrich; BONSS, Wolfgang; LAU, Christoph. The Theory of Reflexive Modernization: Problematic, Hypotheses and Research Programme. Theory, Culture \& Society, v. 20, n.2, p. 1-33, 2003.

BETTI, Mauro. Educação Física e Sociedade. São Paulo: Movimento, 1991.

BETTI, Mauro. "Ensino de primeiro e segundo graus: educação física para quê?". Revista Brasileira de Ciências do Esporte, v. 13, n. 2, p. 282-287, 1992.

BETTI, Mauro. Por um a teoria da prática. Motus Corporis, v. 3, n. 2, p. 73-127, dez. 1996.

BRACHT, Valter. Educação Física \& ciência: cenas de um casamento (in)feliz. ljuí, Editora Unijuí, 1999.

BRASIL. Parâmetros curriculares nacionais: Ensino Médio: Educação Física/ Secretaria de Ensino Fundamental. Brasília: MEC/SEF, 2000.

BRASIL. Lei № 13.415, DE 16 de fevereiro de 2017. Reforma do Ensino Médio, fev. 2017. Disponível em: <http://www.planalto.gov.br/ccivil 03/ ato2015-2018/2017/lei/L13415.htm> Acesso em: 2 ago. 2017a.

BRASIL. Base Nacional Comum Curricular. Disponível em: <http://basenacionalcomum.mec. gov.brl> Acesso em: 15 maio 2017b.

DAOLIO, Jocimar. Da cultura do corpo. Campinas, SP: Papirus, 1994.

FREIRE, João Batista. Educação de corpo inteiro: teoria e prática da Educação Física. São

Paulo: Scipione, 1989. 
GARÍGLIO, José Ângelo. O papel da formação inicial no processo de constituição da identidade profissional de professores de educação física. Revista Brasileira de Ciências do Esporte, v. 32, n. 2-4, p. 11-28, dez. 2010.

GIDDENS, Anthony. As consequências da modernidade. São Paulo: Editora da UNESP, 1991.

GIDDENS, Anthony. Para além da esquerda e da direita. O futuro da política radical. São Paulo. Editora da UNESP, 1996.

GIDDENS, Anthony. A vida em uma sociedade pós-tradicional. In: BECK, Ulrich; GIDDENS, Anthony; LASH, Scott. Modernização reflexiva: política, tradição e estética na ordem social moderna. São Paulo: Editora UNESP, 1997. p. 73-134.

GIDDENS, Anthony. Família. In: GIDDENS, Anthony. 0 mundo em descontrole: o que a globalização está fazendo de nós. Tradução de Maria Luiza X. de A. Borges. Rio de Janeiro: Record, 2000. p. 61-75.

GIDDENS, Anthony. Modernidade e Identidade. Rio de Janeiro: Zahar, 2002.

GIDDENS, Anthony. Sociologia. 4. ed. Porto Alegre: Artmed, 2005.

GIMENO SACRISTÁN, José. O Currículo: uma reflexão sobre a prática. 3. ed. Porto Alegre: Artmed, 2000.

HILDEBRANDT, Reiner; LAGING, Ralf. Concepções abertas no ensino da educação física. Rio de Janeiro: Ao Livro Técnico, 1986.

KUNZ, Elenor. Educação Física: ensino e mudança. ljuí: Ed. Unijuí, 1991.

KUNZ, Elenor. Esporte: uma abordagem com a fenomenologia. Movimento, v.6, n. 12, p. 1-13, 2000.

LARA, Larissa Michelle; BARBOSA-RINALDI, leda Parra; MONTENEGRO, Juliana; SERON, Taiza Daniela. Dança e Ginástica nas abordagens metodológicas da educação física escolar. Revista Brasileira de Ciências do Esporte, v. 28, n. 2, p. 155-170, jan. 2007.

LASH, Scott; WYNNE, Brian. Introdução. In: Risk Society: Towards a new modernity. Londres: SAGE, 1992, p. 1-8.

MAFFEI, Willer Soares; VERARDI, Carlos Eduardo Lopes; PESSÔA FILHO; Dalton Müller. Formação inicial do professor de educação física: produções acadêmicas entre 2005 - 2014. Motrivivência, v. 28, n. 49, p. 146-163, dez.2016.

MOREIRA, Antonio Flávio Barbosa. A recente produção científica sobre currículo e multiculturalismo no Brasil (1995-2000): avanços, desafios e tensões. Revista Brasileira de Educação, n. 18, p 65-81, set. /dez. 2001.

MOREIRA, Laine Rocha et al. Apreciação da Base Nacional Comum Curricular e a Educação Física em Foco. Motrivivência, v. 28, n. 48, p. 61-75, set. 2016.

NEIRA, Marcos Garcia. Educação Física Cultural: carta de navegação. Arquivos em Movimento, v.12, n.2, p.82-103, jul./dez. 2016.

OLIVEIRA, Vitor Marinho de. Educação Física Humanista. São Paulo: Ao Livro Técnico, 1985. 
PARANÁ. Diretrizes Curriculares da Educação Básica: Educação Física. SEED, Paraná, 2008.

RAMOS, Valmor. O conhecimento do professor: a prática pedagógica como referência. In: NASCIMENTO, Juarez Vieira do; FARIAS, Gelcemar Oliveira. Construção da identidade profissional em educação física: da formação à intervenção. Florianópolis: Ed. da UDESC, 2012, p. 447-464. (Coleção temas em movimento, v. 2).

SÃO PAULO. Secretaria de Estado da Educação. Proposta Curricular do Estado de São Paulo: Educação Física Ensino Fundamental Ciclo Il e Ensino Médio. São Paulo, 2008.

SOARES, Carmen Lúcia et al. Metodologia do ensino de Educação Física, São Paulo: Cortez, 1992.

SOARES, Carmen Lúcia. Educação Física: conhecimento e especificidade. Revista Paulista de Educação Física, supl. 2, p. 6-12, 1996.

SOUZA, Juliano de. A atualidade de um clássico: Educação Física Humanista de Vitor Marinho de Oliveira. Revista Brasileira de Educação, v. 23, e230078, 2018.

TANI, Go et al. Educação Física escolar: fundamentos de uma abordagem desenvolvimentista. São Paulo: Editora da USP, 1988.

VANDENBERGHE, Frédéric. Globalização e individualização na modernidade tardia: uma introdução teórica à sociologia da juventude. Mediações, v. 19, n. 1, p. 265-316, jan./jun. 2014.

ZABALA, Antoni. A Prática Educativa: como ensinar. Porto Alegre: Artmed, 1998. 